\title{
The clouded leopard in Taiwan
}

\author{
Alan Rabinowitz
}

\begin{abstract}
There has never been a thorough survey of Taiwan's clouded leopard population, and some believe it may no longer survive there. The author conducted a preliminary survey in 1986 and discovered that the last reported sighting of the species was in 1983.
\end{abstract}

Swinhoe (1862) described Taiwan's clouded leopard as a distinct species, Leopardus brachyurus, but it is now recognized as a subspecies, Neofelis nebulosa brachyurus. There has never been a definitive survey of the status of the clouded leopard in Taiwan; its past and present population numbers are a mystery. This cat was already believed to be reduced to dangerously low levels over 15 years ago (Wayre, 1969).

McCullough (1974) reported the clouded leopard as possibly still existing in remote regions of the Central Mountain Range of Taiwan. However, direct evidence of this cat has been so sparse in recent years that some Taiwanese believe it to be extinct.

In September 1986, I travelled throughout Taiwan in an attempt to discover whether the clouded leopard might still exist. The solitary and nocturnal behaviour of this cat makes it difficult to observe, and this is compounded by the fact that the clouded leopard is partly arboreal and does not leave prominent signs in the form of faeces and scrapes along roads or trails (Rabinowitz et al., 1987). This lack of marking behaviour makes the cat virtually impossible to track, and may be indicative of small or isolated populations (Schaller and Crawshaw, 1980; Rabinowitz and Nottingham, 1986). Because of these difficulties and because of time constraints, I concentrated on interviewing aboriginal hunters, forestry officials and villagers, regarding recent sightings and/or killings of clouded leopards, and the status of potential prey species in the area.
I interviewed 70 people: of 33 reported sightings of the clouded leopard, seven occurred within the last five years, three were between five and ten years ago, and 23 occurred more than ten years ago. Many of the people interviewed, who had never seen clouded leopards, knew of this cat being seen or killed by old hunters who had since died. These sightings dated from at least 20 years ago, often from the Japanese occupation (1895-1945), when Japanese soldiers paid high prices for clouded leopard skins.

The seven recent sightings were between 1981 and 1983; five occurred within the present boundaries of Yu-Shan National Park, and two in the Tawu Mountain region (vicinity of Peitawushan and Nantawushan). The most recent record was from Nantawushan where, in August 1983, a young clouded leopard, whose back molars had not yet erupted, was found by Mr Chang Wan-fu of Tunghai University in a hunter's snare (see China Post, 26 August 1984). The specimen was borrowed from the owner of the snare, stuffed, and photographed. This information appeared reliable, but I did not substantiate it.

In 24 instances people remembered where the animals had been seen; 13 were in trees and 11 on the ground. This supports speculation that the clouded leopard uses trees, but is not strictly arboreal (Selous and Banks, 1935; Rabinowitz et al., 1987). Sightings occurred in a wide range of habitats and elevations, from coastal hardwood forests to coniferous forests as high as $3000 \mathrm{~m}$.

Oryx Vol 22 No 1, January 1988 
In the 1970s Taiwan effected laws that restrict the hunting of any animal and the ownership of any new firearms. Previously, people hunting with guns and dogs would sometimes encounter a clouded leopard, which would be chased by the dogs and brought to bay (Selous and Banks, 1935). Although most hunters claimed that the clouded leopard was never hunted specifically, they all admitted to killing them if encountered.

In recent years, hunters have switched to snares and steel-jaw traps, all of which are readily available at local stores. Often, scores of traps are set in an area and are left for up to two weeks before being checked again. Hunting as a way of life, however, has declined in Taiwan. The decline may have begun during the Japanese occupation, when most hill tribes were forced to move away from their hunting areas, and since then other factors such as better education, the loss of forests and the scarcity of easily accessible wildlife have contributed. Although the fact that there are fewer hunters may have contributed towards the drop in clouded leopard sightings over the last ten years, the lack of recent evidence of clouded leopards is due primarily to the disappearance of this cat from most areas of the island.

The data from this preliminary survey indicate that the clouded leopard might still exist in the Yu-Shan National Park and in the Tawu Mountain area, one of the few remaining large low-to-middle-elevation forested areas in Taiwan. The cat may also survive in other remote pockets but deforestation and poaching of the cat's prey threaten the clouded leopard's long-term survival. Encroachment, poaching and deforestation of Taiwan's forests have been widespread in the past, and are still major problems. The survey indicated that all the large game species, especially the Taiwan black bear Selanarctos thibetanus formosanus and the Taiwan sambar deer Cervus unicolor swinhoei, are declining rapidly in areas that are within two-days' walking distance of human habitation. Current laws against hunting are not well enforced. Fresh game meat, animal heads and assorted wildlife parts are sold openly in stores and restaurants everywhere.

The Tawu Mountain region should be protected immediately, incorporating as much low Clouded leopard in Taiwan elevation habitat as possible. This area has been recommended for protection before; Severinghaus (1977) indicated that it contained the rare endemic yellow tit Parus holsti, and possibly populations of endemic Swinhoe's and Mikado pheasants, Lophura swinhoei and Syrmaticus mikado.

Detailed forest surveys to look for more conclusive evidence of the clouded leopard, and to assess the status of other large species and their remaining habitat, should be carried out in the Tawu Mountain area and eventually throughout Taiwan. The surveys should also collect historical information from aboriginal hunters. However, initially we need to conduct ecological research on the population dynamics of the large wildlife species in order to assess the minimum size of protected areas necessary.

\section{Acknowledgments}

I would like to thank my hosts in Taiwan for their gracious hospitality and co-operation: $\mathrm{Mr}$ Chang Lung-Sheng, Director-General of Construction and Planning Administration, Ministry of Interior, and Dr Kuo-Shih Hsu, Chief of the National Park Department, Ministry of Interior. I would also like to thank the following individuals for their guidance and assistance during the course of this survey: $\mathrm{Mr}$ Chin-Chao Koh, Dr Sheldon Severinghaus, Dr Jung-Tai Chao, Mr Yin-Lin Wu, and Dr Ling Ling Lee.

\section{References}

Guggisberg, C.A.W. 1975. Wild Cats of the World. Taplinger Publ. Co., New York.

McCullough, D.R. 1974. Status of Larger Mammals in Taiwan. World Wildlife Fund Report. Tourism Bureau, Taipei, Taiwan.

Rabinowitz, A., Andau, P. and Chai, P.P.K. 1987. The clouded leopard in Malaysian Borneo. Oryx, 21, 107111.

Rabinowitz, A. and Nottingham, B. 1986. Ecology and behaviour of the jaguar (Panthera onca) in Belize, Central America. J. Zool. Lond. 210 (A), 149-159.

Schaller, G. and Crawshaw, P.G. 1980. Movement patterns of jaguar. Biotropica, 12, 161-168.

Selous, E.M. and Banks, E. 1935. The Clouded Leopard in Sarawak Sarawak Mus. J. 4 (3), 263-266.

Severinghaus, S.R. 1977. Recommendations for the conservation of the Swinhoe's and Mikado Pheasants in Taiwan. J. World Pheasant Assoc. 111, 79-89.

Swinhoe, R. 1862. On the mammals of the island of Formosa (China). Proc. Zool. Soc. Lond. 23, 347-365.

Wayre, P. 1969. Wildlife in Taiwan. Oryx, 10, 46-56.

Dr Alan Rabinowitz, Wildlife Conservation International, New York Zoological Society, Bronx, NY, NY 10460, USA. 